\title{
Transfer of escape conditioning to extinction of a food-reinforced response
}

\author{
ROGER L. MELLGREN, NABIL HADDAD, DENNIS G. DYCK, and ED ECKERT \\ University of Oklahoma, Norman, Oklahoma 73069
}

Four experiments test the hypothesis that escape learning in response to shock will transfer to a similar food-reinforced response and affect resistance to appetitive extinction. In the first two experiments, subjects were given escape training in a straight alley followed by continuous food reinforcement and then extinction. Prior escape training resulted in greater resistance to extinction of the food-reinforced response as compared to several control procedures. In the third experiment, the escape response was manipulated to be compatible or incompatible with the subsequent food-reinforced response. Greater resistance to extinction was shown when the two responses were compatible. The fourth experiment confirmed and extended this finding. The relationship of the present results to Amsel's theory of persistence was discussed.

A number of investigators have used a procedure that involves the presentation of continuous food and partial shock in the goalbox of a straight alley (Brown \& Wagner, 1964; German, 1969). The increased resistance to extinction that follows such food and shock training relative to a food-only control group has been interpreted as reflecting a functional similarity between shock and nonreward (or of fear and anticipatory frustration). Since both events are assumed to be aversive, it is usually hypothesized that they share some common psychological properties; therefore, training the subjects to run in the presence of anticipated shock leads to greater persistence of responding in the presence of anticipated nonreward. D'Amato (1969), for example, has developed an explanation of increased persistence following food and shock training from the standpoint of frustration theory. However, this type of theory accounts for effects that have generally been small or even nonexistent (Banks \& Torney, 1969; Brown \& Wagner, 1964; Martin \& Ross, 1964).

In unpublished pilot work in our laboratory involving goalbox shock, it was noticed that the most common responses to shock were moving backward and a jerky-jumping motion (see also Fowler, 1963). Since Ross (1964) has presented evidence showing that the kind of response (i.e., running, jumping, or climbing) associated with anticipated nonreward will determine subsequent resistance to extinction of the running response, the generally weak effect of goalbox shock superimposed on a continuous food reinforcement schedule on resistance to extinction may reflect the incompatibility of responses elicited by the shock and the running response. In a further exam-

Reprint requests should be addressed to Roger L. Mellgren, Department of Psychology, University of Oklahoma, Norman, Oklahoma 73069. D. G. Dyck is now at the Department of Psychology, University of Manitoba, Winnipeg, Canada. ination of transfer of persistence related to the common properties of aversive events such as nonreward and shock (or, in stimulus sampling terminology, the partial overlap of the set of stimulus elements produced by nonreward and shock), it seems important to provide a situation where compatible responses will be associated with these different events. In the first two experiments, a period of escape conditioning was given prior to a period of continuous food reinforcement in the runway, followed by extinction. It was hypothesized that if one aversive event (shock) is associated with a particular response (running), and this is followed in extinction by a second aversive event (nonreward fo'lowing continuous food reinforcement), then the prior escape learning should transfer to extinction and produce greater persistence of responding. In the third and fourth experiments, the escape response was manipulated such that it would be either compatible or incompatible with the subsequent response undergoing extinction.

Wong $(1971 \mathrm{a}, \mathrm{b})$ has used a procedure he terms "coerced approach," which is conceptually similar to the procedure in the present experiments. In Wong's most similar condition (1971b), the subject received a .5 -sec shock for engaging in a competing response (any response incompatible with the goal oriented locomotive response) in the first phase of the experiment. He showed that when these punishment-of-competing-responses subjects were given a subsequent phase of food-reinforced training and extinction, they were more resistant to extinction than subjects that were not given the prior punishment treatment. In the present experiment, those subjects given escape training in a straight runway would also be punished for engaging in responses incompatible with the goal-oriented locomotive response, since the termination of shock occurred only when the subject reached the end of the alley. 


\section{EXPERIMENT I}

In the first experiment, one group of subjects received a series of escape conditioning trials in a straight runway followed by continuous food reinforcement and no shock, and finally extinction of the running response (Group EC). One control group (RC), which received the same total number of trials as the experımental group, was food-reinforced on all trials and served as a control for number of runs in the apparatus. A second control group (HC) was run to determine if number of reinforced trials had an effect regardless of the escape conditioning procedure. This group was not run in the runway during the first part of the experiment but were handled and maintained on the food-deprivation schedule. They began food-reinforced training when Group EC was switched to food-reinforced training (Group HC).

\section{Method}

\section{Subjects and Apparatus}

The subjects were 24 experimentally naive male albino rats, 65 days old, of the Sprague-Dawley strain, purchased from the Holtzman Co. The subjects were randomly assigned to one of three groups ( $\mathrm{n}=8)$.

The apparatus consisted of a commercially manufactured straight alley (Hunter), $150 \mathrm{~cm}$ long, $15 \mathrm{~cm}$ high, and $10 \mathrm{~cm}$ wide. The alley was constructed of Plexiglas and a grid floor, had a startbox $30 \mathrm{~cm}$ long, a runway $90 \mathrm{~cm}$ long, and a goal section $30 \mathrm{~cm}$ long. Raising the startbox door operated a microswitch which closed a shock circuit to the grid of the start and runway sections of the alley. The start timer began when the startbox door was raised and stopped when the subject crossed a photobeam $5 \mathrm{~cm}$ inside the runway. The same photobeam started the run timer, which was stopped when the subject crossed a second photobeam $15 \mathrm{~cm}$ from the end of the runway section. The goal limer was started when the second photobeam was crossed and was stopped when a third photobeam $5 \mathrm{~cm}$ inside the goalbox was crossed. A Grason-Stadler shock scrambler (Model 700) was used 1o provide shock to the start and runway sections. A teaspoon mounted in the middle of the far end of the goalbox served as the foodcup. Fractionated and total times were converted to reciprocals, and the results are reported in terms of this speed measure.

\section{Procedure}

For 4 days after arrival in the laboratory, the subjects were allowed ad-lib access to food and water. The subjects were then placed on a 12-g daily food-deprivation schedule with water coninuously available. The deprivation schedule was established 7 days before the start of the experiment. Prior to the start of the experment, all subjects were given 5 Startina Hog Starter pellets (approximately $90 \mathrm{mg}$ each) in addition to the daily $12 \mathrm{~g}$ of laboratory chow.

The experiment proper consisted of three phases in addition to $I$ day of pretraining. During pretraining, Group EC received two 3-mA escape conditioning trials and Group RC received two "eward conditioning trials. The foodcup in the goalbox was batted with two Startina Hog Starter pellets. Group HC was handled briefly but was not exposed to the apparatus.

Escape training. During this phase, Group EC was given 28 r.rials of escape training, 4 per day for 7 days. A trial consisted of placing the subject in the startbox; $3 \mathrm{sec}$ later, the door was opened and the subject received shock until it traversed the runway and entered the goalbox. After the subject entered the goalbox, a guillotine door was closed to prevent retracing. The subject remanned in the goditbou for 15 sec betore beng removed The amount of hock recesced m the sart and runwas sectorns of the alley was increased gratually durng the phase. The subjects recened $3 \mathrm{~mA}$ on Das 1 and 2. $4 \mathrm{~mA}$ on Day 3 and $4,6 \mathrm{~mA}$ on Ddy 5 and 6 . and is m A on Das - Croup RC was glsen 28 trals of reward conditioning during this period On all trials, the subjects were remtorced with two 90-mg Startina Hog Starter pellets, using the same general procedure as Group EC, with the exception that no shock was ever delivered, of course. Finally, Group HC received handling but was not exposed to the apparatus throughout this phase. The subjects were run in rotation in squads of three, one from each group. The intertrial interval was $5 \mathrm{~min}$, as it was in all four experiments. During this phase, the subjects in Groups $\mathrm{EC}$ and $\mathrm{HC}$ received 8 pellets in the home cage in addition to the dally ration of $12 \mathrm{~g}$ in order to equate the intake (and experience with the pellets) of these groups to that of Group RC.

Reward conditioning. During this phase, all groups received 56 trials of continuously reinforced reward conditioning, 4 trials/day for 14 days. The procedure during this phase was identical to that of Group $\mathrm{RC}$ in the first phase for all the groups.

Extinction. This phase consisted of 16 extinction trials, 4 per day for 4 days. The intertrial interval in extinction was also $5 \mathrm{~min}$ in all experiments. During this period, all subjects encountered an unbaited foodcup in the goalbox, where they were confined for $15 \mathrm{sec}$. During this phase, if any subject failed to traverse any section of the runway within $60 \mathrm{sec}$, he was removed from the runway and assigned a time of $60 \mathrm{sec}$ for all remaining sections.

\section{Escape Training}

\section{Results and Discussion}

As can be seen in Figure 1, Group EC showed very rapid acquisition, with the increase in running speeds characteristic of acquisition occurring within the first two trials, obscuring any increase in speeds when the data are plotted as in Figure 1. Terminal differences in this phase were negligible; the last day of this phase was analyzed using a simple one-way analysis of variance. The only difference between groups was in the start speed measures, $F(1,14)=4.28, p<.06$. The run, goal, and total speeds failed to approach an acceptable level of significance; $F(1,14)=2.66, .62$, and 2.40 , respectively.

\section{Reward Conditioning}

The prior escape traming for Group EC resulted in little facilitation or decrement in the subsequent food-reinforced phase. Comparison of Group EC with Group HC showed some differences early in Phase 2 with respect to the goal speed measure, but by the end of Phase 2 there were no significant differences among the groups $[\mathrm{Fs}(2,21)=1.73,1.31$, 1.52 , and 1.01 ; for start, run, goal, and total on the last day of Phase 2, see Figure 1].

\section{Extinction}

Group EC was more resistant to extinction than the two contro! groups (Groups $\mathrm{RC}$ and $\mathrm{HC}$ ) in the goal and total speed measures. Figure 2 shows the differences for each measure for the last day of acquisition and the 4 days of extinction. Repeated measures analyses of variance revealed that the main 


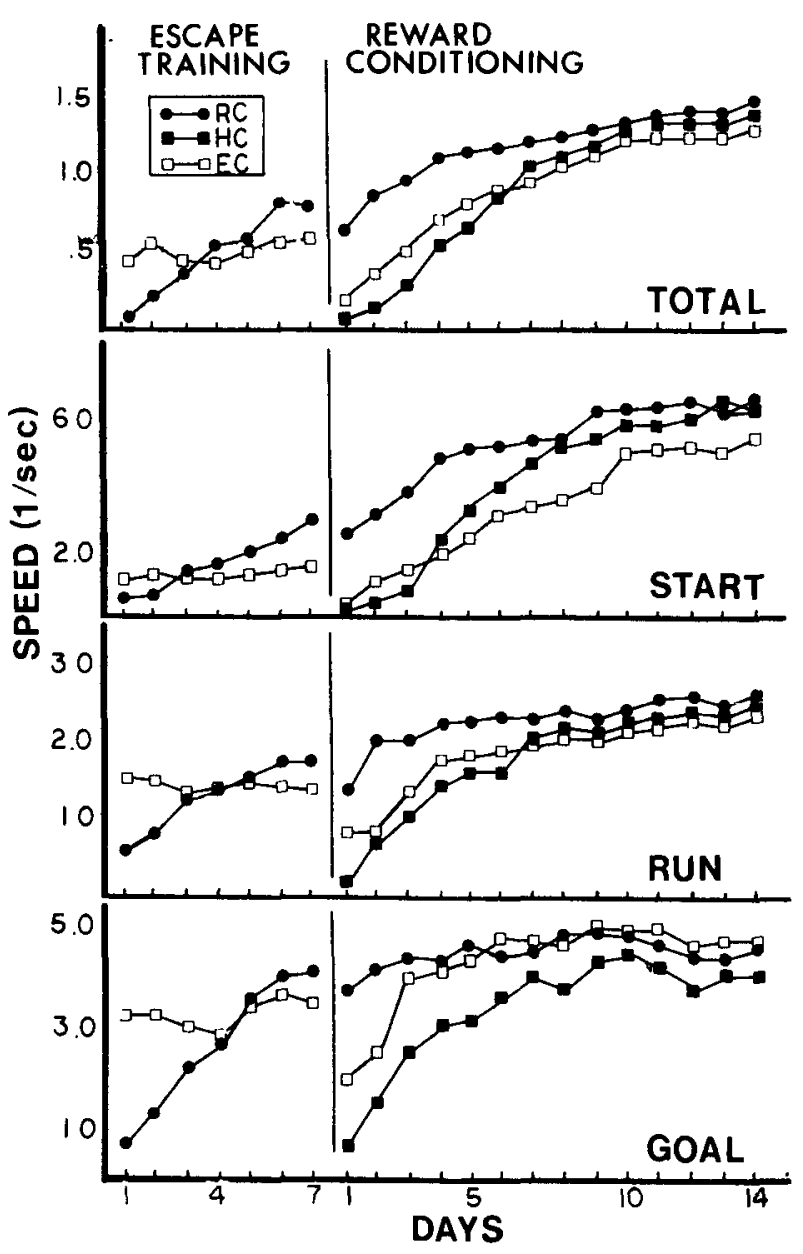

Figure 1. Total, start, run, and goal mean running speeds for the 7 days of escape training and the 14 days of reward conditioning (Experiment I).

effect of groups was significant for the goal speed measure, $F(2,21)=7.82, p<.01$, and the total speed measures, $F(2,21)=3.75, p<.05$. The main effect of days was significant in all analyses.

The data are consistent with the notion that training one response (running) to shock transfers to nonreward due to the similarity of, or generalization between, the psychological effects of shock and nonreward.

\section{EXPERIMENT II}

The first experiment demonstrated that a running response acquired in an escape procedure transfers to a period of food-related extinction and increases persistence of responding. If the mechanism which controls this transfer is the overlap of the aversive aspects of shock and nonreward, then it would be predicted that the degree of aversiveness of the shock used in the escape conditioning phase would affect resistance to extinction (Linden, 1974). The possibility also exists that, with continued nonreinforce- ment, the aversiveness of extinction would build up, producing a monotonically increasing relationship between shock level and subsequent resistance to extinction. Thus, the three-phase procedure used in the first experiment was also used in this experiment, but the groups differed in the amount of escapable shock encountered in the first phase. For each group, a particular level of shock was held constant at $0, .3, .6$, or $1.0 \mathrm{~mA}$ throughout escape conditioning. The group receiving 0 shock in Phase 1 serves as a control for the absence of food reward during the first phase for the escape group. The "initial nonreward effect" (Capaldi, Ziff, \& Godbout, 1970; Spear, Hill, \& O'Sullivan, 1965) refers to a demonstration of increased resistance to extinction when a number of nonrewarded trials precedes rewarded trials which are followed by extinction.

\section{Subjects and Apparatus}

\section{Method}

The subjects were 40 rats like those used in the first experiment. They were assigned randomly to one of four experimental groups $(\mathrm{n}=10)$.

The apparatus was identical to that described in the first experiment.

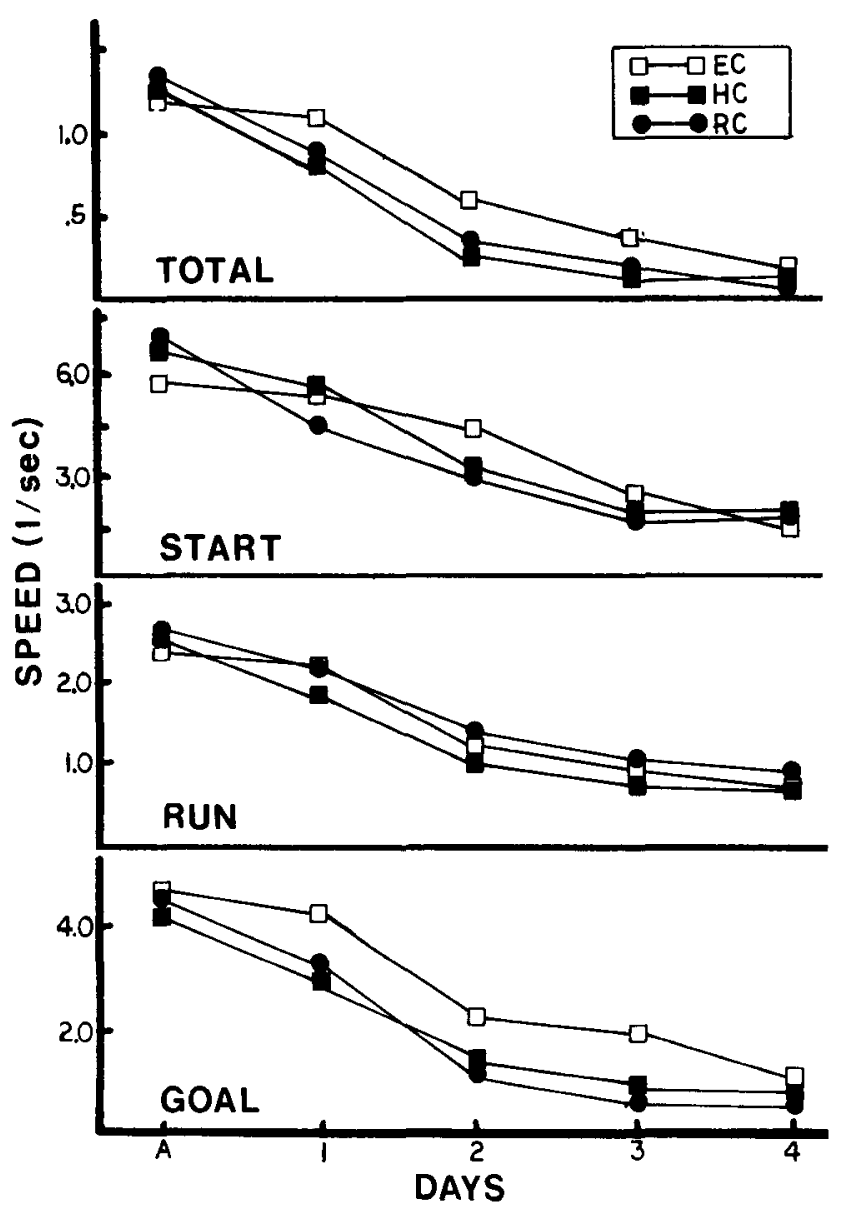

Figure 2. Tolal, start, run, and goai memn running speeds for the last day of acquisition and the 4 das of extinction (Experiment I). 


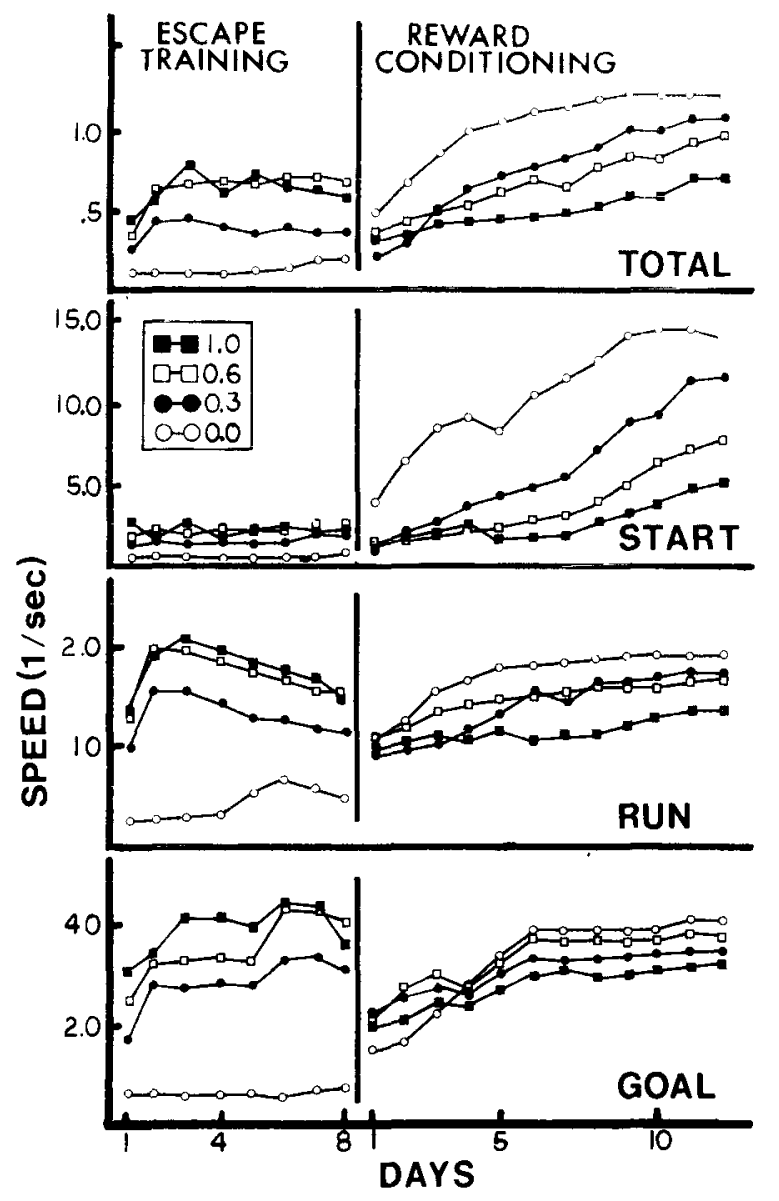

Figure 3. Total, start, run, and goal mean running speeds for the 8 days of escape training and the 12 days of reward conditioning (Experiment II).

\begin{abstract}
Procedure
The experiment proper consisted of the same three phases as in Experiment I The amount of shock received in the start and runway was varied such that each of the four groups received $0, .3, .6$, or $1.0 \mathrm{~mA}$ of shock. Escape training consisted of 30 trials, 4 per day ( 2 trals on the first day) for 8 days. Unlıke the first experıment, the shock level remaned constant throughout this phase. Reward conditionıng was run as in the first experiment, except that only 48 trials were used, 4 per day for 12 days. Extinction was the same as that described in Experiment I, except that it consisted of a total of 28 trials, 4 per day, for 7 days. Since there were asymptotic acquisition differences at the end of the reward conditioning phase in start, run, and total measures, these data were subjected to a rate transformation (Anderson, 1963).
\end{abstract}

\section{Escape Training}

\section{Results and Discussion}

As can be seen in Figure 3, speeds were generally positively related to shock level in escape training. Analyses of variance on start, run, goal, and total speeds on the last day of escape training showed that groups was a significant source of variance, $F(3,39)$ $=13.92,16.16,28.50$, and 35.78 , respectively, with all ps $<.001$. Tukey's post hoc comparisons confirmed some of the rather obvious differences between groups. The 1.0- and .6-mA groups did not differ from each other in any measure, but were sigmuficantly faster than the .3- and $0-\mathrm{mA}$ groups $(p<.05)$. The only exception to this was the lack of differences between the 1.0-, .6-, and .3-mA groups in the goal speed measure. All groups receiving greater than 0-level shock were faster than the $0-\mathrm{mA}$ group $(p<.05)$.

\section{Reward Conditioning}

The occurrence of shock in Phase 1 exerted a large influence on subsequent speeds to food reward, as shown in Figure 3. Generally, the higher the level of shock in the escape-training phase, the slower the running speeds in the reward-conditioning phase. Analyses of variance on the last day of reward conditioning revealed a significant effect of groups in the start, run, and total measures, $F_{s}(3,36)=$ $5.36,3.79$, and 7.43 , respectively, all ps $<.05$, but not in the goal measure, $F(3,36)=2.24, p>.05$.

\section{Extinction}

Groups 1.0, 0.6, and 0.3 were more resistant to extinction than Group 0.0 in the goal speed measure. This difference was revealed in an analysis of variance of the goal speeds where a significant effect due to level of escapable shock in the escape conditioning phase was found, $F(3,36)=4.23, p<.05$. Tukey's post hoc comparisons on the goal speed measure showed that Group 0.0 was less resistant to extinction than all others. The $.3, .6$, and 1.0 groups did not differ from each other. Figure 4 s'ıows the extinction performance in the various segments of the runway, and the total measure. As previously noted, start, run, and total speeds were transformed using Anderson's (1963) procedure because of terminal reward conditioning differences. The rate of extinction relative to the terminal level of reward acquisition performance indicates that Group 1.0 was more persistent than all other groups, $\mathrm{Fs}(3,36)=$ $8.20,10.71$, and 9.34 , all ps $<.05$, for start, run, and total measures, respectively. In terms of the absolute speeds, however, there was no difference between groups in the start measure. In the run and the total measures, the 1.0 group was superior to the other groups, which did not differ from each other. Thus, the rate transformation and the raw speeds produce somewhat different conclusions, neither one of which can be interpreted unambiguously. This is particularly a problem when considering the start measure, where terminal acquisition differences were extremely large. For these reasons, the goal measure is the most straightforward to interpret.

In summary, Experiment II shows again that prior escape training increases resistance to extinction of a food-reinforced response; it also shows that the effect depends, to some extent at least, on the level of shock used in the escape training. The failure of impressive differences to emerge as a result of differ- 
ent levels of shock suggests that the similarity of the aversiveness of the shock and nonreward is not the important consideration in producing increased persistence of responding. However, the level of food reinforcement was rather small in the present experiment, and perhaps all of the shock levels were much more aversive than the nonreward encountered in extinction, making variations in the shock level ineffective. This suggests that the manipulation of both the levels of shock and of food reward might be fruitful in future work (e.g., Linden, 1974).

Increased response persistence in appetitive extinction following prior escape conditioning is not dependent on the experience of initial nonreinforcement trials (the INE) prior to continuous food-reinforced acquisition. Thus, the INE is eliminated as an explanation of increased persistence shown by the escape groups.

\section{EXPERIMENT III}

The previous experiments support the view that escape from shock through a particular response (running) will increase persistence of that response in face of another aversive event, nonreward. It therefore follows that escape from shock through a response incompatible with running would decrease resistance to appetitive extinction of the running response. The logic parallels that developed by Ross (1964). In order to test this hypothesis, one group in the present experiment received escape training involving a running response (Group $R$ ), while a second group received escape training involving a jump-up response (Group J). Both groups were then given a period of continuous food reward in a straight runway, followed by a period of extinction training. If the escape response associated with shock transfers to extinction of food-reward running, then it would be expected that Group R would be more resistant to extinction than Group $J$.

In addition to determining whether escape training can increase or decrease resistance to extinction of a food-reinforced response, the present experiment involved the test of a specific hypothesis concerning the mechanism underlying these effects. It might be assumed that prior experience with an aversive event (like shock) somehow decreases the reactivity of the subject to subsequent aversive events (like nonreward). Decreased reactivity to the aversiveness of nonreward would be expected to result in greater resistance to extinction. To test this possibility, a control group which received inescapable shock during the first phase of the experiment was included (Group N). A control group receiving placements in the escape apparatus, but no shock, was also included (Group C).

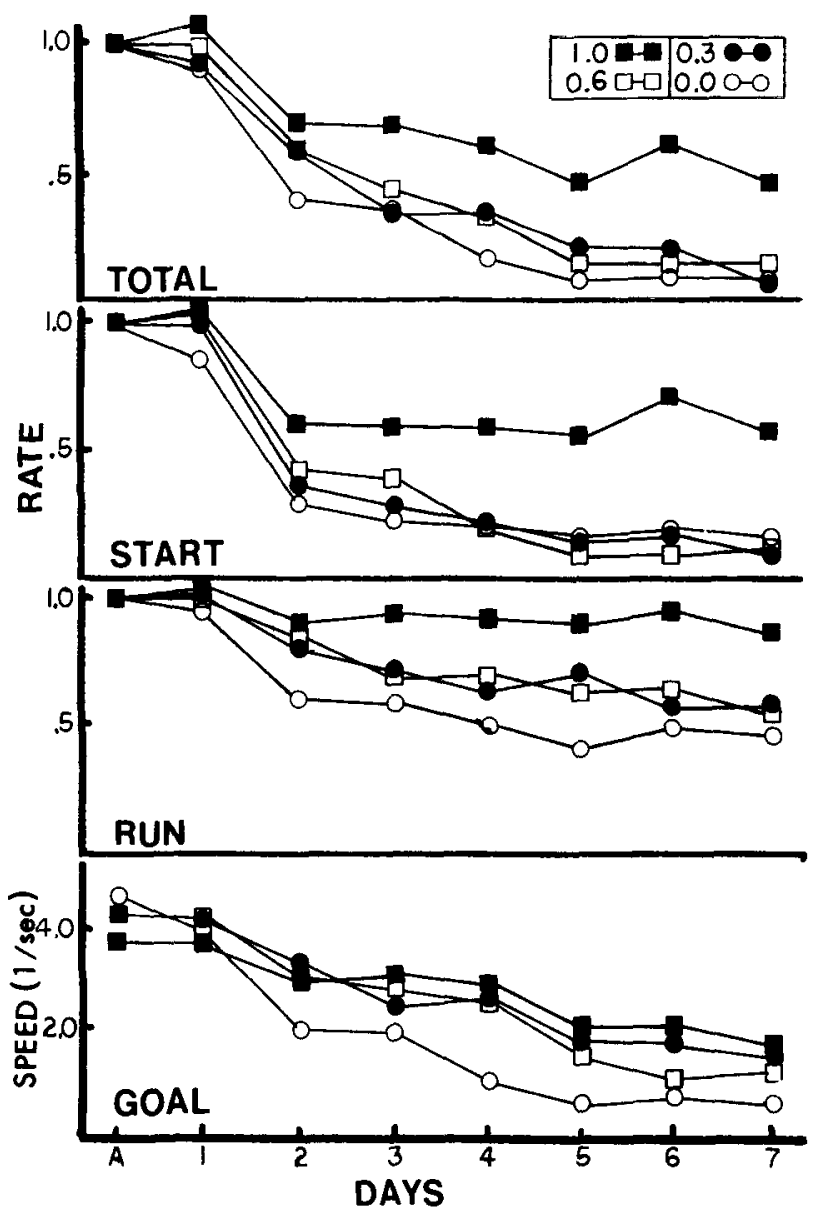

Figure 4. Mean rates of the total, start, and run measures and mean running speeds of the goal measure for the last day of acquisition and the 7 days of extinction in Experiment 11. (Mean rate for the last day of acquisition is $\mathbf{1 . 0}$ by definitiond

\section{Subjects and Apparatus \\ Method}

The subjects were 40 rats like those used in the first experiment. The subjects were randomly assigned to one of four groups $(n=10)$.

The apparatuses used in this experiment consisted of a wooden shock box and a straight-alley runway. The shock box was $90 \mathrm{~cm}$ long, $14 \mathrm{~cm}$ wide, and $30 \mathrm{~cm}$ high. It was divided by a Plexiglas guillotine door into two easily discriminable chambers, one white and the other black. A manually retractable wooden ledge constructed of $0.9-\mathrm{cm}$-thick plywood could be inserted through a slot located $15 \mathrm{~cm}$ from the bottom at the far end of the white compartment. When inserted into the box, the ledge was $12 \mathrm{~cm}$ wide $\times 12 \mathrm{~cm}$ long. Both chambers had a grid floor consisting of aluminum tubes, $1 \mathrm{~cm}$ in diameter and spaced $4 \mathrm{~cm}$ apart. The grid floor was attached to the same shocker used in Experiments I and II.

The second apparatus consisted of a wooden straight-alley runway covered with a hardware cloth top. The floor was wooden, and the sides were lined with white cardboard paper. It was $15 \mathrm{~cm}$ wide $\times 16 \mathrm{~cm}$ high. The start, run, and goal sections were 52 , 112 , and $45 \mathrm{~cm}$ long, respectively. Guillotine doors separated the start from the run section and the run from the goal section. A teaspoon mounted at the center of the far end of the goalbox served as the foodcup. Start, run, goal, and total speeds were obtained as in Experiments I and II. 


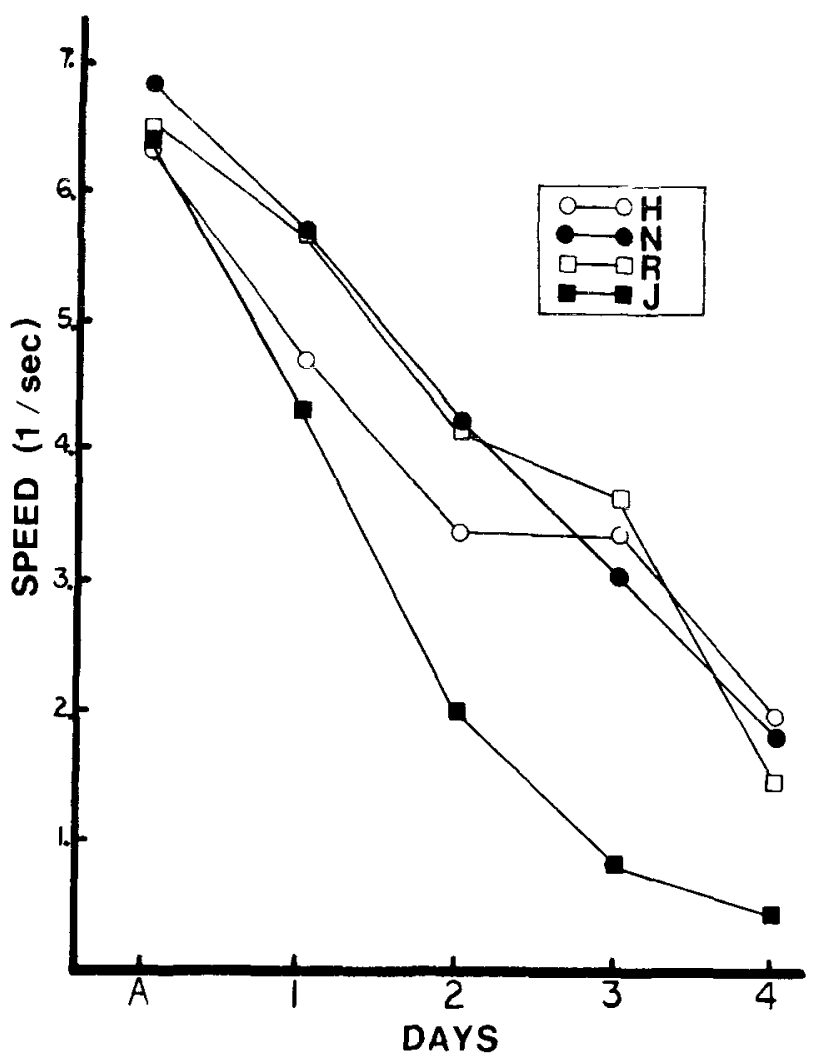

Figure 5. Mean running speeds of the start measure for the last day of acquisition and the 4 days of extinction (Experiment (II).

\section{Procedure}

Upon arrival in the laboratory, the subjects were individually housed and allowed free access to food and water for 5 days. On the sixth day, subjects were placed on the same deprivation and handling schedules used in Experiments I and II. Five days after the start of their food-deprivation schedule, the subjects started the first phase of the experiment.

Escape training. This phase lasted for 7 days, with 4 trials per day in the shock-box apparatus. Three groups recelved a scrambled shock of $0.8 \mathrm{~mA}$ intensity in the white compartment. The subjects in the fourth group (Group $\mathrm{H}$ ) did not recelve any shock: using a quasi-yoked procedure, they were placed in the white compartment for the same amount of time as the shock-escape groups (approximately $10 \mathrm{sec}$ ). One group was allowed to escape shock by running into the unshocked black compartment (Group R), and a second was allowed to escape by jumping onto the ledge (Group J). The subiects were placed in the white compartment and the shocker was activated. One second later, the guillotine door was opened for the subjects in Group R, allowing them to escape shock by runnıng into the black compartment. For subjects in Group J, the guillotine door remained shut, and after $I$ sec of shock. the ledge was inserted into the white compartment, allowing them to escape the shock by jumping up onto the ledge. The third group (Group N) was placed in the white compartment for the same amount of time as the other groups $(10 \mathrm{sec})$. but the subjects were not allowed to escape a 1-sec 0.8-mA shock.

Reward conditioning. Following the first phase, all subjects were pretrained to run in the straight alley at 1 trial per day for 2 days. No running tıme measurements were taken for these pretraining trials. All subjects were then run four trials per day for 9 days in the straight alley. During this phase, all groups were on a continuous remforcement schedule like that used in the previous experiments.

Fixtinction Following acquistion of the running response, the subjects were give, 4 exunction trals per day for 4 days using the same procedure described in previous experiments

\section{Escape Training}

\section{Results and Discussion}

The subjects in Groups $\mathbf{R}$ and $\mathbf{J}$ learned to run or jump to escape from shock as soon as the opportunity to make the response was provided. It was noted that a majority of the subjects in Group $\mathrm{N}$ tended to run around in circles and, occasionally, jump in response to the inescapable shock. It appeared that this locomotory pattern observed in Group $\mathbf{N}$ was an unconditioned response to the shock, since no response(s) terminated shock for this group. It could also be the case that running minimized the aversı veness of the shock.

\section{Reward Conditioning}

Unlike the previous two experiments, acquisition of the running response to food reinforcement was not affected by prior escape conditioning. In the previous experiments, all phases of the experiments were carried out in the same apparatus, but in the present experiment the escape training apparatus (by design) was markedly different from the reward conditioning apparatus. Apparently, this change in apparatus from the escape training phase to the reward conditioning phase prevented the decremental effects of prior escape conditioning from or urring in the reward conditioning phase. Analyses of variance on the last day of acquisition resulted in Fs for the groups main effect which were less than 1.0 for all measures (start, run, goal, and total).

\section{Extinction}

Figure 5 shows the extinction speeds of the four groups for the last day of acquisition and the 4 days of extinction in the start measure, and shows that Group J was much less resistant to extinction than the other three groups. This was confirmed in a repeated measures analysis of variance, where a signigicant main effect of groups was found, $F(3,36)=$ $3.16, p<.05$. No other analysis revealed any significant effects. with the exception of the trials main effect in all the analyses [smallest $F(3,108)=42.42$, $p<.001$ in start]. Using Duncan's procedure for comparing groups confirmed that Group $\mathbf{J}$ was less persistent than the other three groups $(p<.05$ in all cases). The differences between Group $\mathrm{H}$ and Groups $R$ and $N$ apparent on the first 2 days of extinction failed to reach the .05 level of significance.

The response associated with escape training does appear to be an important determinant of subsequent resistance to extinction of a food-reinforced re- 
sponse. When subjects were required to jump up on a ledge in order to escape from shock, they were much less resistant to extinction than subjects that were required to run to escape from shock. The jump-up response is incompatible with the running response, and if transfer between the aversive properties of shock and continued nonreward occurs, it would be expected that Group J would be less resistant to extinction. Moreover, the change in apparatus (i.e., brightness, texture, size, and even the room in which they were located) between the escape and rewardextinction phases would seem to preclude explanations of the observed effects based on external cues.

Although the differences between Groups $\mathrm{R}$ and $\mathrm{J}$ follow nicely from the previously developed theoretical notions, the lack of difference between Groups $\mathbf{R}$ and $\mathbf{N}$ is somewhat troubling. In this regard, it should be noted that the dominant response tendency for subjects in Group $\mathrm{N}$ during the escape phase was some type of locomotion. It is conceivable that this locomotion was accidentally reinforced by the termination of shock, even though the latter was not contingent on any form of responding. Such accidental reinforcement, or perhaps the simple association of shock and locomotion in time, may be sufficient to produce effects on later extinction. Indeed, Wong (1971a) suggested that simple contiguity of response and shock is sufficient to produce the kind of transfer effects obtained in the present experiments. Another plausible hypothesis is that shock in the absence of any defined escape response may "de-emotionalize" the rat, so that resistance to extinction of the subsequent foodreinforced response is greater because extinction is less aversive. Of course, the phenomenon of "learned helplessness" is procedurally similar in that it depends on prior exposure to inescapable shock.

The lack of significant differences between Groups $\mathrm{R}$ and $\mathrm{H}$ is also disturbing. There was some evidence of greater persistence in Group $R$ in the first 2 days of extinction only. In this regard, it should be noted that the running response during the escape conditioning phase of the present experiment can only be described as a "short run," since all the subject had to do was move one body length to escape shock. In the previous experiments, the subject was required to run down an alley to escape. It would be expected that the "short-run" response used in the present experiment would produce less resistance to extinction since the response required of the rat in extinction is a "long run." In addition, it would be expected that the effects on resistance to extinction would be strongest in the start measure (i.e., the start measure is like a "short run"), as was found. The next experiment was designed to test this hypothesis.

\section{EXPERIMENT IV}

To test this "short-run" hypothesis, it is necessary to provide a situation where one group of subjects is trained to escape shock via a short-run response and another group is trained to escape via a long-run response. In the first phase, one group received escapable shock which was delivered only in the startbox of the Plexiglas alley. This group (SR) is analogous to Group $\mathrm{R}$ in the previous experiment, since only a "short run" was required to escape shock. A second group (LR) received shock in the start and the run sections of the alley, and had to run to the goalbox to escape shock.

In addition to the short-run and long-run groups, two groups that received inescapable shock in the first phase were included. One group received inescapable shock throughout the runway; i.e., the startbox door was opened but no contingency was in effect (Group LS). The other group was given an inescapable shock in the startbox by keeping the startbox door closed (Group SS). In addition, a fifth group, which was placed in the runway ivith no shock or reward present, was included (Group NS). This group would again control for the "initial nonreward effect."

\section{Subjects and Apparatus \\ Method \\ The subjects were 50 rats like those used in the previous experiment. They were assigned randomly to one of five groups $(n=10)$. One subject died during the cour of the study, leaving Group LR with 9 subjects. \\ The apparatuses used in this experiment were two different straight-alley runways. One was the wooden runway used in Experiment III, and the other was the Plexiglas runway described in Experiment 1.}

\section{Procedure}

Upon arrival in the laboratory, subjects were housed two to a cage and allowed free access to food and water for 5 days. On the sixth day, subjects were placed on the same food-deprivation and handling schedules used in the previous experiments. Seven days after the start of the food-deprivation schedule, the subjects started in the first phase of the experiment.

Escape training. This phase lasted for 10 days, each consisting of four trials in the Plexiglas shock runway. The subjects were run individually in squads of six. The intensity of the scrambled shock was held constant at $0.8 \mathrm{~mA}$ thoughout this phase. Subjects in the two escape conditioning groups were placed in the startbox; $3 \mathrm{sec}$ later, the startbox door was opened and shock was delivered simultaneously. The subjects in Group LR received shock in the start and run sections and therefore had to traverse the runway to the goalbox to escape the shock, generally replicating the procedure of Experiments I and II. The subjects in Group SR received shock in the startbox only and therefore had to simply move out of it to escape the shock. Group LS was placed in the start section and shock was delivered in all sections of the runway (goalbox included) upon opening the startbox door. No escape response was therefore possible. The subjects in Group SS also received inescapable shock. They were placed in the start section, the door 


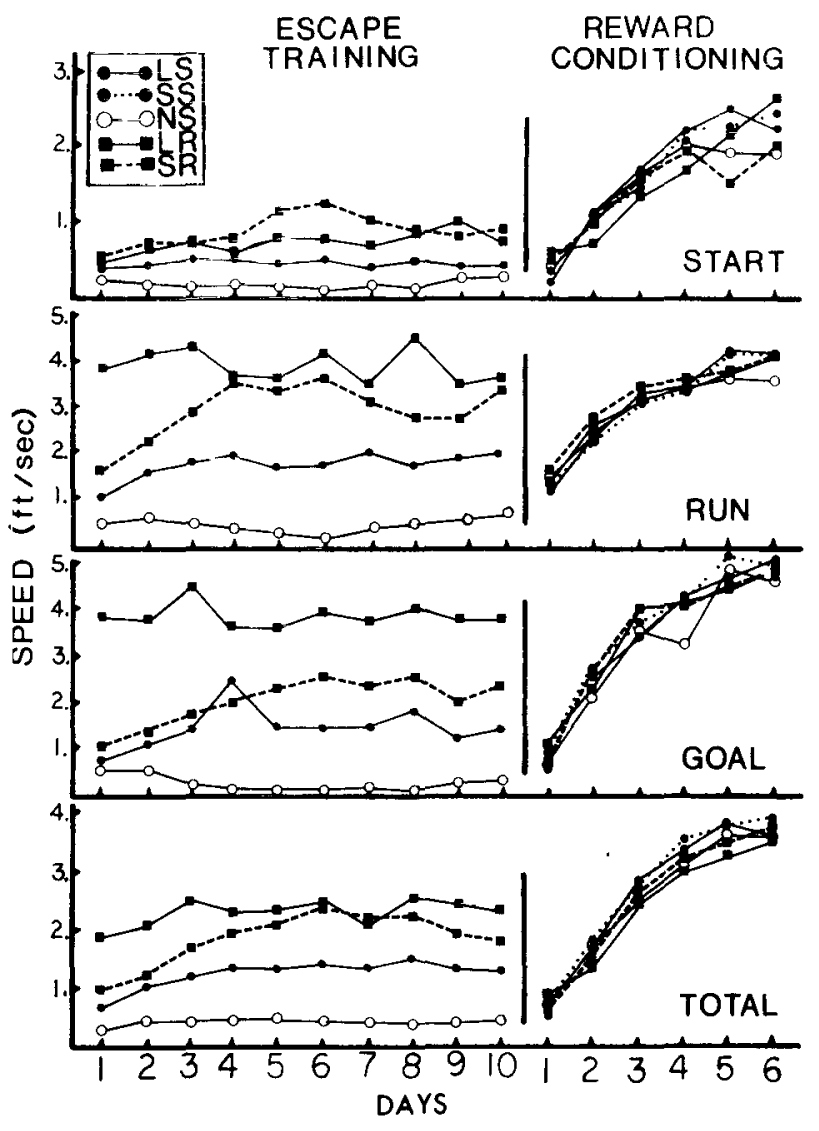

Figure 6. Total, start, run, and goal mean running speeds for the last 10 days of escape training and the 6 days of reward conditioning (Experiment IV).

remained shut and shock was delivered, thus physically preventing the occurrence of any running responses in the runway.

The duration of the shock delivered to Groups LS and SS was yoked to that received by Groups LR and SR (i.e., half the subjects in Groups LS and SS were yoked to LR subjects, and half were yoked to SR subjects). Finally, the subjects in Group NS were placed in the start section, the door was opened, but no shock was delivered.

Reward conditioning. Following the first phase, all subjects were given two pretraining trials of reinforced reward conditioning in the wooden runway. All groups were then given 4 trials per day for 6 days of contınuously reinforced reward conditionıng similar to the previous experıments.

Extinction. This phase consisted of 16 extinction trials, 4 per day for 4 days, using the same exunction procedure as in the previous experiments.

\section{Escape Training}

\section{Results and Discussion}

As can be seen in Figure 6, speeds of the two escape groups (LR and SR) were generally superior to those of the other groups. Group NS showed no evidence of acquisition. It was noticed that some subjects in Group LS did learn to run down the alley, even though no contingencies were in effect. No times were recorded for subjects in Group SS, since they were physically confined to the startbox. Where contingencies were in effect (Groups LR and SR), acquisition was very fast and reflected the type of contingency. Inded, acquisition for Group LR was so rapid that presenting the data by days obscures the increase in speeds which occurred over the first few trials of acquisition. Figure 6 shows that the running response of Group SR was not maintained throughout the runway. For Group LR, however, a consistent running response was maintained in the three sections of the runway. Therefore, the establishment of a short run response for Group SR and a long run response for Group LR was successful.

\section{Reward Conditioning}

Acquisition of the running response to food reinforcement was not affected by the preceding escape conditioning phase. Figure 6 shows that the five groups acquired the positively reinforced running response at almost the same rate. Analyses of variance were run on the data of the last day of acquisition for the start, run, goal, and total speeds. All Fs were less than 1.0, showing no terminal acquisition differences.

\section{Extinction}

Group LR was more resistant to extinction than all other groups in all measures except the start. Figure 7 shows the speeds of the five groups for the last day of acquisition and the 4 days of extinction. Repeated measures analyses of variance for unequal Ns were performed on the four measures. The main effect of groups was significant in all except the start measure, $F(4,44)=2.55, p=.051$. In the run, goal, and total measures, Fs $(4,44)$ were $4.73,2.73$, and 2.89 , respectively ( $p<.05$ in all cases). Tukey's pairwise comparisons were conducted to analyze group differences in the run, goal, and total measures. Group LR was more resistant to extinction than all other groups $(p<.05)$. No other differences between groups were significant. All analyses showed the main effect of days to be highly significant, while the interactions of Groups by Days were nonsignificant.

The results of the present experiment show that when the escape response and the food-reinforced response are compatible (Group LR), resistance to extinction is increased relative to conditions where the two responses are incompatible (Groups LS and SS) or only slightly similar in topography (Group SR). In Experiment III, it was shown that when the two responses are incompatible (Group J), resistance to extinction is decreased.

These results seem to conflict with a recent investigation reported by Banks (1973). Using a withinsubject design, Banks trained subjects to approach 
food reward via two incompatible responses: climbing and running. During acquisition, the running response was reinforced on a partial reinforcement (PRF) schedule while the climbing response received intermittent punishments (IP) superimposed on a PRF schedule. Testing with continuous punishment (CP) revealed that intermittent punishment of the climbing response resulted in increased resistance to $\mathrm{CP}$ for both the climbing and the running responses. Banks concluded that the compatibility or the incompatibility of the response receiving IP training and that undergoing $\mathrm{CP}$ does not have any incremental or decremental effect on the subject's resistance to $\mathrm{CP}$. To the degree that IP training theoretically resembles the transfer studies reported here, Banks' finding seems to be in disagreement with these data. It should be noted that the within-subject procedure used by Banks did not control for any sequential effects (Capaldi, 1967), since all trial sequencing was completely randomized. If, due to this randomization procedure, reinforced running trials were occasionally preceded by punished climbing trials, an association between the running response and the aversive stimulus of punishment could have been established. There is strong evidence to indicate that when such sequential associations occur in a withinsubject design (Mellgren \& Dyck, 1972) and when punished trials precede reinforced trials in a betweensubject design (Dyck, Mellgren, \& Nation, 1974), an increase in resistance to extinction occurs for the response that had been preceded by nonreward or by punishment during acquisition. Accordingly, Banks may have sequentially conditioned the running response as well as the climbing response, thereby masking any decremental effects due to response incompatibility. Alternatively, Banks' procedure may be dissimilar enough from the present one that his data would not reflect the importance of response topographies.

\section{GENERAL DISCUSSION}

The present experiments seem to allow a number of conclusions. In general, it is clear that escape training influences resistance to extinction of a foodreinforced response. This transfer effect has been shown to occur when the escape and food-reward apparatuses are the same (Experiments I and II), or when they are different (Experiments III and IV). The magnitude of the transfer effect may be dependent on the shock levels used in escape training (Experiment II). The transfer does not appear to be due to an "initial nonreinforcement effect" (Experiments II and IV). Similarly, increased resistance to extinction does not seem to be due to the deemotionalizing or desensitizing of the subjects to aversive events (like nonreward) as a function of prior experience with shock (Experiment IV). Habit-
TRANSFER OF ESCAPE CONDITIONING

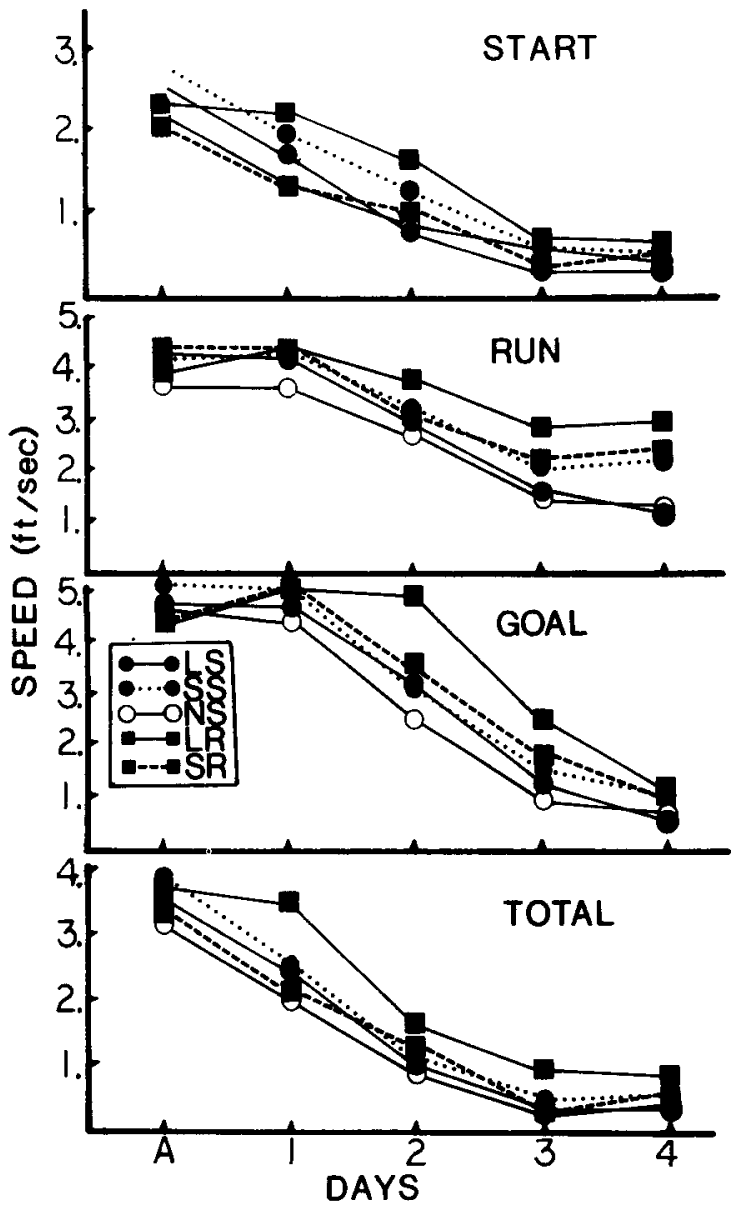

Figure 7. Total, start, run, and goal means running speeds for the last day of acquisition and the 4 days of extinction (Experiment IV).

uation of competing responses during the escape training phase does not appear to account for the transfer effects. The group receiving all rewarded trials (Group RC) in Experiment I, the no-shock group (INE control or Group 0) in Experiment II, and the no-shock group (Group NS) in Experiment IV all had seemingly ample opportunities to have any competing responses habituate during the initial phase of each experiment, yet these groups were not highly resistant to extinction. Greater numbers of running trials do not produce greater resistance to extinction, as shown by the fact that subjects given food reward for the same number of trials as the escape group were less resistant to extinction in Experiment I. Finally, but more importantly, the transfer effect does depend on the compatibility of response topographies between the escape phase and the extinction phase (Experiments III and IV).

The data may be interpreted in the general framework of "response persistence" theory (Amsel, 1972a, b). It would be assumed that during escape conditioning, the shock, which is a disruptive stimulus, $S_{x}$, would become associated with the ongoing instrumental response, $R_{0}$. During the sub- 
sequent food extinction phase, nonreward acts as a disruptive stimulus, $S_{\mathbf{x}}{ }^{\prime}$, and to the degree that there is generalization between $S_{x}$ and $S_{x}{ }^{\prime}, R_{0}$ will tend to be increased in persistence. In addition to the primary disruptive stimulus, $S_{x}$, anticipation of $S_{x}$ may take the form of $r_{x}-S_{x}$, which would also be associated with $R_{0}$. The transfer between $r_{x}-s_{x}$ and the usually hypothesized frustration-associated stimuli characteristic of a food-reinforced response undergoing extinction $\left(\mathrm{r}_{\mathrm{f}}-\mathrm{s}_{\mathrm{f}}\right)$ would serve an important role in determining extinction performance. The relative importance of reinforcement is not specified in the above explanation, and consistent with Wong (1971a), at present we prefer to emphasize the contiguity of events rather than appealing to reinforcement notions. If a reinforcement notion is invoked, however, it is interesting to note that it is negative reinforcement (escape from shock) that would be determining the rate of extinction of a positively reinforced response.

An alternative explanation to the one developed above might emphasize the responses which do not occur rather than those that do. It could be postulated that the increase in resistance to extinction came about because the prior escape training resulted in the punishment of competing responses (Wong, $1971 \mathrm{~b}$, invoked this kind of notion). In Experiment III, the jump-escape group (Group J) was less resistant to extinction than the running escape group (Group R), but Group R was not different from the control groups (Groups $\mathrm{H}$ and $\mathrm{N}$ ). If only a punishrnent of competing responses explanation is to account for the findings, then apparently Group $J$ was less resistant to extinction because all running tendencies would result in punishment. Of course, the hypothesized punished running response would have to be an extremely short running response because of the confining nature of the apparatus used in escape conditioning. If we extend this explanation to the group that was conditioned to run (Group R), they should have had competing responses (stopping, sniffing, rearing, etc.) punished and should therefore have been more resistant to extinction than the controls. In Experiment III, Group R was not more resistant to extinction than the controls. Therefore, although we do not feel compelled to discount totally a punishment of competing responses explanation, by itself it does not seem sufficient to explain all of the present data. Some appeal must be made to an explanation based on the escape response itself in addition to considering those responses which are punished because they do not terminate the shock.

\section{REFERENCES}

AmsEL. A. Inhibition and mediation in classical and instrumental learning. In R. A. Boakes \& M. S. Halliday (Eds.), In hibution and learning. New York: Academic Press, 1972. (a)
AmSEL, A. Behavioral habituation, counterconditioning and a general theory of persistence. In A. H. Black \& W. F. Prokasy (Eds.), Classical conditioning II: Current research and theory. New York: Appleton-Century-Crofts, 1972. (b)

ANDERSON, N. H. Comparison of different populations: Resistance to extunction and transter. Psychological Review, 1963, 70, $162-179$.

BAnks, R. K. Generality of persistence: The role of stimulus and response tactors in persistence to punishment. Leaming and Motivation, 1973, 4, 218-228.

BANKS, R. K., \& TORNEY, D. Generalization of persistence: The transter of approach behavior to differing aversive stimuli. Cunadian Journal of Psychology, 1969, 23, 268-273.

Brown, R. T., \& W AGNER, A. R. Resistence to punishment and exinction following training with shock or nonreinforcement. Journal of Experimental Psychology, 1964, 68, 503-507.

CaPALDI, E. J. A sequential hypothesis of instrumental learning. In K. W. Spence \& J. T. Spence (Eds.), The psychology of learning and motuation (Vol. 1). New York: Academic Press, 1967

Capaldi, E. J., Ziff, D. R., \& Godnout, R. C. Extinction and the necessity or non-necessity of anticipating reward or nonrewarded trials. Psychomomic Sctence, 1970, 18, 19.21.

Dyck, D. G., Mellgren, R. L., \& Nation, J. R. Punishment of appetitively reinforced instrumental behavior: Factors affecting response persistence. Joumal of Experimental Psychology. 1974, 102, 125-132.

D'AMATo, $M$. R. Instrumental conditioning with negatlve reinforcement. In M. H. Marx (Ed.), Learming: Processes. New Yotk: MacMillan, 1969. Pp. 76-118.

Fowler, H. Facilitation and inhibition of performance by punishment: The effects of shock intensity and distribution of trials. Journal of Comparative and Physiological Psychology, 1963. 56. $531-533$.

German. D. C. Resistance to punishment and extinction in one situation as a function of training with shock or nonreinforcement in a different situation. Psychonomic Science, $1969,17,271-273$.

LINDEN, D. R. The effect of intensity of intermittent punishment in acquisition on resistance to extinction of an approach response. Animal Leaming \& Behavior, 1974, 2, 9-12.

MARTIN. B., \& Ross. L. E. Effects of consummatory response punishment on consummatory and runway behavior. Journal of Comparative and Phvsiological Psychologv, 1964. 58. 243-247.

Mellgren, R. L.. \& Dyck, D. G. Partial relnforcement effect, reverse partial reinforcement effect, and generalized partial reinforcement effect within subjects. Journal of Experimental Psychology, 1972, 92, 339-346.

Ross. R. R. Positive and negative partial-reinforcement extinction effects carried through continuous reinforcement, changed motivation and changed response. Joumal of Experimental Psychology, 1\%64, 68, 492-502.

Spear. N. E.. Hill, W. R., \& O'Sullivan, D. J. Acquisition and extunction after initial trials without reward. Joumal of Experiminial Psychology, 1965, 69, 25-29.

WONG, P. T. P. Coerced approach to shock and resistance to punishment suppression and extinction in the rat. Journal of Comparative and Physiological Psychology, 1971, 75. 82-91.(a)

WONG, P. T. P. Coerced approach to shock, punishment of competing responses, and resistance to extinction in the rat. Journal of Comparaive and Physiological Psychology. 1971. 76. $275-281 .(\mathrm{b})$
(Received for publication July 28, 1975; revision accepted December 15,1975 .) 